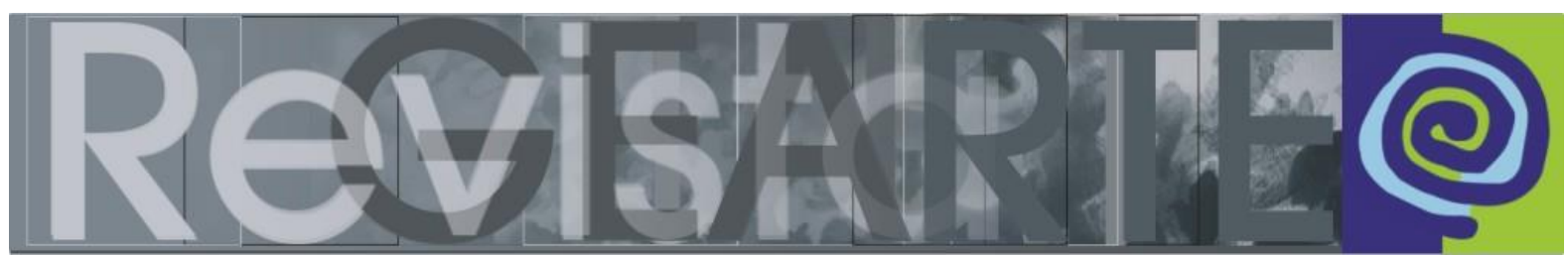

ISSN 2357-9854

\title{
Arte como experiência: ensino/aprendizagem em Artes Visuais
}

\author{
Fábio Wosniak (Universidade do Estado de Santa Catarina - UDESC, \\ Florianópolis/SC, Brasil) \\ Jociele Lampert (Universidade do Estado de Santa Catarina - UDESC, \\ Florianópolis/SC, Brasil)
}

\begin{abstract}
RESUMO - Arte como experiência: ensino/aprendizagem em Artes Visuais - Este artigo apresenta reflexões acerca dos conceitos de arte como experiência e os processos de ensino/aprendizagem em artes visuais, tangenciando os campos da Arte, Arte-Educação e o ensino da pintura. Seu principal eixo consiste na abordagem metodológica que vem sendo pesquisada no Grupo de Estudos Estúdio de Pintura Apotheke e nas aulas de Graduação e Pós-Graduação em Artes Visuais da Universidade do Estado de Santa Catarina (UDESC).
\end{abstract}

PALAVRAS-CHAVE

Arte como experiência. Ensino/aprendizagem em artes visuais. Arte. Arte-Educação.

ABSTRACT - Art as experience and the teaching/learning processes in visual arts - This article presents some reflections on the concepts of art as experience and the teaching/learning processes in visual arts, touching on the fields of Art, Art Education and teaching of painting. Its main axis consists of the methodological approach that has been researched by the Apotheke Painting Studio Study Group and the Undergraduation and Graduate Studies in Visual Arts at Santa Catarina State University (UDESC).

KEYWORDS

Art as experience. Teaching/learning in the visual arts. Art. Art Education.

Deveria ser igualmente corriqueiro saber que a compreensão estética parte do solo, do ar e da luz dos quais brotam coisas esteticamente admiráveis. John Dewey

Refletir sobre o processo de ensino/aprendizagem no contexto do ensino superior requer compreender que a pesquisa em Arte e Arte-Educação envolve fazer perguntas e procurar respostas que possibilitem o entendimento sobre como produzir, estudar e ensinar arte. De acordo com Sullivan (2005), os educadores geralmente procuram adaptar práticas tradicionais de pesquisa das ciências humanas na elaboração dos métodos de investigação. Por exemplo, no início dos anos 1960, arteeducadores empreenderam esforços para a validação de uma teoria de campo (ARNESTINE, 1965; ECKER,1965; EFLAND e EISNER,1964; e KAUFMAN, 1959). A questão principal pairava sobre a Arte como disciplina, e se era possível construir um 
arcabouço teórico sobre os quais as estruturas exploratórias de conhecimento poderiam ser sustentadas. Anos mais tarde, o uso de métodos de pesquisa qualitativos em pesquisa educacional encontrou espaço na Arte-Educação (BRESLER, 1994; CHALMERS, 1981; EISNER, 1985 e 1991; MAY, 1993; STOKROCKI, 1997). Assim, os esforços em torno de fundamentar a adequação da teoria de Arte-Educação forneceram referências para o professor, como uma fonte de conhecimento confiável, e para a prática em sala de aula e a comunidade, como bases viáveis para reflexões de pesquisa. Essa aproximação fundamentada foi percebida como forma de avaliar mais de perto a autenticidade de aprender e ensinar arte. Como resultado, é notável que as concepções de Arte-Educação mudaram, assim como os seus métodos, formas e modelos de pesquisa foram (ou estão sendo) adequados.

Para Pareyson (2001), há três definições de Arte, que compreendem o campo do saber e a área do conhecimento. São definições tradicionais, que se justapõem e coexistem: Arte como fazer, como conhecimento e como expressão. Em diferentes momentos da História da Arte, o pensamento acerca do conceito de Arte multiplicouse, e assim estendeu-se seu sentido. "Estas diversas concepções colhem caracteres essenciais da Arte, conquanto não sejam isoladas em si e absolutizadas." (PAREYSON, 2001, p. 22)

A filosofia de Pareyson revela que o aspecto mais relevante da Arte é o realizativo, que vai ao encontro da iminência das ideias de "forma" e "formatividade". Contudo, o autor ressalta em sua teoria da estética que toda atividade humana possui lados que envolvem o fazer e o pensar, compreendendo obras especulativas que abrangem ética e estética. Pareyson esclarece que se a Arte é expressão, é produto da inteligência laboriosa; se é fazer, é reflexo da invenção; e se é conhecimento, ressoa as experiências.

Já a filosofia da Arte como experiência de Dewey (1934) revela que o trabalho artístico perpassa todo o organismo humano, iniciando no devaneio e na produção imaginativa. Porém, necessita de ordenação, ou seja, requer que o artista domine conhecimentos específicos - de natureza técnica, relacionados ao fazer artístico. O filósofo, no desenvolver de sua teoria, comenta sobre a tomada de consciência no processo da experiência estética. Ela consiste em ter o conhecimento de todo 
processo de elaboração da obra de arte - da imaginação à técnica. A filosofia de Dewey centra-se principalmente em torno da experiência estética, que é intimamente ligada ao ato criador. Para o autor, a experiência estética é a forma mais elaborada de apreender conhecimento, pois unifica e potencializa processos de inteligência. $O$ estético, como afirma Dewey, unifica o desenvolvimento "esclarecido e intensificado de traços que pertencem a toda experiência normalmente completa" (DEWEY, 2010, p. 125).

Nesta perspectiva, os dois filósofos convergem para uma concepção de produção em Arte que não dicotomiza o fazer do pensar. Tampouco os autores demonstram que o fazer em arte é uma produção de qualquer devaneio da imaginação - a sua execução faz parte de um projeto laborioso, perpassando regras e técnicas. Ali a execução e criação se fundem, a produção não consiste exclusivamente no resultado da imaginação e muito menos na execução de um projeto com materiais. $A$ obra de arte é sempre um desafio ao pensamento, pois evoca materiais e a sua organização através da imaginação.

Outro autor que trata da relação entre Arte e técnica é Alberto Tassinari (2001). Em seu texto "A obra de arte e o espectador contemporâneo", Tassinari apresenta essa relação e a condição da artisticidade da obra de arte em seu processo de elaboração e conclusão. O autor trata inclusive de objetar que a artisticidade não é revelada exclusivamente pelo espectador, ou pelo artista e o seu fazer como núcleo, visto que na fase de formação da arte moderna ela ganha espaço no pensamento estético. Contudo, nesta perspectiva de reflexão, existe um pensamento acerca da produção do espaço moderno, para que esta apreensão da artisticidade possa também ser atribuída pelo espectador. Tassinari evoca o pensamento de que a artisticidade da obra não sugere dons artísticos, mas sim uma compreensão de que diante de uma obra pronta há um processo anterior inteiramente responsável por ela. É também essa artisticidade proporcionada por uma obra de arte a responsável pela experiência estética, da qual irão emergir teorias modernas do fazer artístico (TASSINARI, 2001).

Desta forma, a abordagem metodológica que vem sendo pesquisada e desenvolvida semanalmente no que se refere ao ensino da pintura no Grupo de 
Estudos Estúdio de Pintura Apotheke, que se estende para a Graduação e PósGraduação em Artes Visuais, segue reflexões da Educação como reconstrução da experiência (DEWEY, 2010). Compreende-se que experiência não é algo que se oponha à natureza, pela qual se experimenta ou prova a natureza. Pelo contrário, a experiência é uma fase da natureza, podendo ser uma forma de interação, pela qual dois elementos entram (situação/contexto e agente/sujeito), e são assim modificados. Seguindo o pensamento de Teixeira e Westbrook (2010, p. 37), "não é possível separar vida, experiência e aprendizagem, pois simultaneamente vivemos, experimentamos e aprendemos". Nesta perspectiva, a experiência educativa é uma experiência inteligente (intelectual) da qual participa o pensamento. É através dele que se passa a perceber as relações e a continuidade antes despercebidas. Ou seja, de acordo com Dewey (1971), o conceito de Educação é definido pelo processo de reconstrução e reorganização da experiência, pelo qual atribui-se sentido e que habita as escolhas futuras.

Compreendendo Arte e Arte-Educação como experiência, procuramos instaurar em nossas práticas educativas metodologias que dialoguem, mas que também avancem para uma reflexão crítica do contexto e do próprio sujeito, que pesem o ser artista, professor e pesquisador.

Ao vincular estágios sobre a introdução e o processo pictórico a disciplinas da Graduação em Artes Visuais, especificamente disciplinas sobre o ensino das Artes Visuais - como cultura visual - torna-se evidente que além de conhecer as técnicas (teorias metodológicas) e os conteúdos (História da Arte), os estudantes, principalmente os da Licenciatura, desenvolverão uma reflexão crítica sobre a produção em Arte, e não exclusivamente sobre o Ensino de Arte. Tal condição, a de uma reflexão crítica sobre a prática docente em Artes Visuais, é gerada somente pelo condicionamento e articulação entre teoria e prática, no que confere de fato ação saber/fazer - e sobretudo sentir/pensar. Sendo assim, uma das metodologias do Grupo de Estudo Estúdio de Pintura Apotheke que tem sido levada às aulas da Graduação e Pós-Graduação em Artes Visuais consiste em partir de projetos práticos que envolvem exercícios de processos plásticos e resolução de problemas, sempre baseados em exemplos de artistas. Os projetos são desenvolvidos de forma 
processual com finalidade avaliativa, e os critérios são observados em cada etapa do trabalho. Não há separação entre quem ensina e quem produz, no sentido da reflexão crítica como condição de uma formação artística, tanto para os professores quanto para os artistas. Ancoramos nossa prática no sentido inverso: partimos do estudo de teorias, dos exemplos de artistas, e adensamos o processo de construção plástica para a resolução de problemas de pesquisa, com base em Arte. Buscamos compreender que o eixo gerador do fazer artístico é o trabalho e uma potência para a problemática da pesquisa que engendra o pensamento do artista-professor.

O espaço físico é o que ambas as instâncias (teoria e prática) têm em comum: tanto as aulas quanto os projetos são realizados no ateliê de pintura da Universidade. Isso evidencia uma descontinuidade no que tange sobretudo à Pós-Graduação, não somente do sentido de possibilitar o desenvolvimento de estudos práticos, mas principalmente da real articulação entre a teoria e a prática. $\mathrm{O}$ desafio de teorizar a prática (do estúdio de Arte) requer, conforme Sullivan (2005), a construção de uma estrutura robusta e defensiva para considerar a relação entre as teorias e as práticas que fornecem o conhecimento sobre como a Arte pode ser estudada/produzida e ensinada/aprendida. Sobre a relação entre teoria e prática, fundamentamos nossos estudos a partir das seguintes reflexões:

- em primeiro lugar, a identificação de um percurso de questões teóricas e uma ampliação do componente relevante para evidenciar a noção de que a prática artística é um esforço de multidisciplinaridade ancorada no fazer arte;

- apenas uma estrutura pode servir como fórum para considerar debates no campo e assegurar que os limites que constroem discussões em curso são assuntos para revisão contínua;

- estudos de pesquisa que são aceitos podem ser fixados e criticados no domínio particular de teoria e prática;

- as mais recentes abordagens para pesquisa, como o uso de métodos visuais (BANKS, 2001; EMMISON; SMITH, 2000; PINK, 2001; ROSE, 2001) e análise qualitativa de dados por computador (FIELDING; LEE,1998; GAHAN; 
HANNIBAL, 1998; TESCH, 1990), podem ser avaliados em termos do domínio da teoria e prática em Arte-Educação;

- finalmente, a estrutura oferece a possibilidade de a prática artística ser prontamente traduzida para outras disciplinas do discurso da pesquisa se o propósito o exigir. Desta maneira, a cultura da pesquisa permanece fundamentada nas teorias e práticas de arte.

Partindo do contexto de que todo objeto artístico poderá ter dimensões políticas, discursivas e pedagógicas, compreende-se a pratica no ateliê de pintura como processo de um fazer criativo, onde inclui-se a reflexão crítica e a produção plástica por meio da experimentação - e vice-versa - e concebendo que a pintura poderá ser uma representação imaginária, mas também que incontestavelmente denota derivações sobre a estética. Neste sentido, a pintura não é uma técnica, e sim uma tradição, pois seu saber/fazer também é um saber/julgar, ou formas de saber pensar, conforme Duve (2012, p. 147).

O Grupo de Estudos Estúdio de Pintura Apotheke ${ }^{1}$ tem produzido oficinas e micropráticas, para além de exposições. Aquelas ressoam o uso da referência de Dewey (1934) com o fazer pictórico - no sentido de evidenciar o conceito de experiência pelo processo de ensino/aprendizagem — , visto que a pintura é tida como eixo gerador do pensar e do fazer, do saber/sentir. Adicionalmente, além dos projetos finalizados que adentram escolas e outros ateliês, o Grupo instaura redes e conexões com outros projetos.

1 O Estúdio de Pintura Apotheke deriva suas ações de extensão, oferecendo oficinas de pintura, minicursos com prática artística, conversas com artistas-professores, aulas abertas e ações que visam oportunizar a prática pictórica. O objetivo é propiciar o estudo de processos pictóricos, bem como da possibilidade de ensino que envolve a pintura, não como meio tradicional, mas sim em um campo expandido. Desta forma, o espaço do estúdio torna-se ampliado para práticas que envolvem a investigação artística no ensino e no processo de criação. As ações são desenvolvidas e organizadas em parceria com os participantes do Grupo de Estudos Estúdio de Pintura Apotheke (UDESC), do Grupo de Pesquisa [Entre] Paisagens e são idealizadas, criadas e produzidas pela professora Dra. Jociele Lampert (DAV/PPGAV). Fonte: <http://www.apothekeestudiodepintura.com>. 
Desta forma, a concepção metodológica artística paira sobre o ensino e a pesquisa no campo das Artes Visuais, pois a pergunta que nos move é: "Onde está a Arte na Arte-Educação?"

Em disciplinas voltadas para o Ensino de Graduação, tanto para a formação pedagógica quanto para a formação artística, trabalha-se na produção de imagens e sons que compreendem o território artístico no sentido da apropriação ou colagem (conceitual). Assim, objetiva-se formas de desenhar, publicar e fazer investigação, combinando essas qualidades à criação artística e à reinvindicação em formas de pesquisa ou projetos artísticos. Investigar problemas educativos por meio da criação artística, ou mesmo pesquisar problemas artísticos por meio da própria linguagem artística, é uma forma de responder à pergunta que nos move. Tais questões podem assemelhar-se a abordagens como a investigação baseada em Arte, ou mesmo a questões que permeiam a $A / R /$ Tografia. No entanto, nossas reflexões sobre as concepções didático-pedagógicas decorrem dos estudos da Arte como experiência.

Apesar de a filosofia da Arte como experiência de John Dewey ter sido elaborada no século passado, sua teoria continua relevante para pensar a ArteEducação contemporânea e principalmente a relação entre 0 ser artista e 0 ser professor. A filosofia da Arte como experiência defendida por John Dewey compreende que a Arte envolve todo o organismo humano de maneira mais significativa, mais do que a Ciência (DEWEY, 2010). Esse envolvimento implica as características mais complexas e elvadas do pensamento.

Nos estudos de Shusterman (1998) sobre a obra de arte como experiência, o autor indica que

[...] Dewey sutenta, portanto, que a arte - modo de atividade carregado de significações passíveis de serem imediatamente possuídas e apreciadas - é o ponto culminante da natureza, e a 'Ciência' é a servidora que conduz os eventos naturais a esse feliz resultado. (SHUSTERMAN, 1998, p. 241)

O que Dewey vai defender em toda sua teoria, além de ressaltar a importância da experiência estética como fundamental para o desenvolvimento humano, é não destituir o pensamento intelectual da imaginação e da criação. Dewey ressalta que 
tanto a Arte como a Ciência são frutos de elaborações humanas sofisticadas, que ambas podem suscitar uma experiência estética em seus praticantes.

\title{
Artes Visuais como Experiência ou o pensamento de Dewey como Base Teórica ${ }^{2}$
}

\begin{abstract}
Desde há muito tempo que já não se fala com a experiência, a partir da experiência, desde a experiência. Só são ditas algumas poucas coisas acerca da experiência. Fala-se muito, e em todos os tons imagináveis, acerca daquilo que acontece, daquilo que ocorre.

Carlos Skliar
\end{abstract}

A obra de John Dewey, Art as Experience, publicada e originalmente editada por Jo Ann Boydston (1934), teve sua tradução para a língua portuguesa em 2010, pela Editora Martins Fontes. Antes da publicação do pensamento filosófico de Dewey sobre uma Filosofia da Arte no Brasil, o autor já era precursor das reformas de ensino em diversos estados brasileiros. Diante dos debates acerca do pensamento deweyano para a Educação, é relevante colocar que seus estudos sobre Educação e Arte, embora tenham sido formulados antes da primeira metade do século $X X$, continuam expressivos para a contemporaneidade. Isso se dá tendo em vista que uma de suas ideias expoentes é a de que "a arte é o locus paradigmático dos valores, e a criação e o prazer advindo da arte são o protótipo dos objetivos dignos da condição humana" (DEWEY, 2010, p. 10).

A filosofia pragmática de Dewey não se refere exclusivamente à ação, mas o que o autor deflagra nesta corrente pragmática é uma teoria filosófica do pensamento e do sentimento, onde o pensamento norteia a ação e o sentimento reconhece as consumações dispostas por ela - uma conscientização unificada pelo sentir e agir. John Dewey foi o filósofo norte-americano mais relevante da primeira metade do século XX. Seu pensamento baseava-se principalmente na convicção moral de que "democracia é liberdade" - uma sociedade democrática prepara todos os indivíduos, de maneira igualitária, assegurando seus benefícios por meio de formas variadas da vida associada. Nessa perspectiva, a educação deve proporcionar aos sujeitos um interesse sobre as questões sociais e culturais, inerentes ao espírito humano,

2 Esta seção é composta de excertos da dissertação de Mestrado de Fábio Wosniak (2015). 
permitindo assim que as mudanças sociais aconteçam sem ocasionamentos de desordem (DEWEY, 1959).

Para o filósofo, a configuração da disposição humana pode ser possível diante de diversos agentes, mas a escola, segundo o autor, ainda é o espaço-chave para que uma filosofia da experiência se concretize como uma "realidade manifesta". Uma filosofia da experiência no âmago da Educação exige que professores sejam conhecedores exímios do seu processo de aprender, e que estejam com seus conjuntos de práticas em constante estado de reflexão. Caso contrário, corre-se o risco de que sua prática pedagógica não passe de um aglomerado de dogmas sem qualquer exame crítico (DEWEY, 2011). Dessa forma, Dewey sustenta a ideia de que nenhuma reflexão sobre processos educacionais é viável sem levar em conta os contextos nos quais estes estão inseridos.

No tocante à Arte, Dewey apresenta questões relevantes para os professores. Em uma publicação de 1998, o autor se pergunta como a Arte "ajudaria a viver melhor a vida cotidiana. Ele [Dewey] se pergunta: como professores de todas as áreas poderão fazer uso de "lições" de arte (entendidas em termos experienciais) para melhorarem o seu ensino?" (BARBOSA, 2001, p. 20-21).

A prerrogativa mais importante para pensarmos na atualização do conceito de experiência cunhado por Dewey é a de recusar as verdades absolutas e as dicotomias. Dewey defende um princípio de continuidade em toda sua filosofia, onde essa continuidade confere uma unidade, que nada se aproxima de imutabilidade. Para Dewey, unidade implica flexibilidade e continuidade de interações (AMARAL, 2007).

Amaral (2007, p. 39) explica que a unidade na teoria deweyana trata

(...) de uma unidade apoiada na flexibilidade das interações e aqui poderíamos perfeitamente acrescentar a palavra "sociais", sem que com isso estivéssemos prejudicando a clareza do pensamento do autor, mas, pelo contrário, reforçando-a. Trata-se ainda de uma unidade que pressupõe a diversidade e poderíamos igualmente acrescentar, dos "espíritos", sem incorrer em qualquer distorção do seu pensamento.

A unidade presente na filosofia de John Dewey une a relação do indivíduo ao meio, aquela entre o homem e o mundo. Compreender o conceito de unidade presente 
na filosofia deweyiana torna-se fundamental para apreender o conceito de Arte como experiência e de Estética. Dewey não abandona as qualidades holísticas, historicistas e organicistas na sua filosofia. O autor busca as "origens estéticas nas necessidades naturais, na constituição e nas atividades do organismo vivo" (SHUSTERMAN, 1988, p. 233). A estética pragmatista de John Dewey, segundo Shusterman (1988, p. 231), "ocupa a posição ideal para reorientar e revigorar a filosofia da arte contemporânea". De acordo com o primeiro, "as oposições entre mente e corpo, alma e matéria, espírito e carne originam-se todas, fundamentalmente, no medo do que a vida pode trazer" (DEWEY, 2010, p. 89).

Assim, já vemos esboçada uma contraposição com as teorias dualistas (corpo $x$ alma, teoria x prática), ou seja, com aquelas teorias estéticas onde os valores principais eram os de praticar distinções entre Arte e Vida. Dewey considera a criatura viva em toda a sua totalidade, cabendo uma filosofia que compreenda a articulação do homem com o seu meio, onde a experiência é a "chave-mestra" para revelar a vitalidade unificada da experiência singular e estética entre o homem e a Arte.

A noção de Arte presente na obra de John Dewey reside na relação que a criatura viva tem com seu ambiente, o naturalismo deweyiano torna-se necessidade para toda obra de Arte. Neste sentido, a função da Arte é unificar a vitalidade consciente presente na vida humana, pois as obras de Arte qualificadas não geram experiências estéticas especializadas - elas aprimoram a percepção, a comunicação, originando fontes de energia e inspiração. A experiência estética é a responsável por ampliar e aprimorar todas as inquietações humanas. Shusterman (1998, p. 238) explica que a função da Arte para Dewey:

(...) não reside em algum fim particular, especializado, mas sim em satisfazer a criatura viva de maneira global, servindo a fins variados e, acima de tudo, aumentando a nossa experiência imediata, que nos revigora e vitaliza, assim, a realizar qualquer fim que busquemos.

Para John Dewey, a arte deveria se situar ao lado das coisas da experiência comum da vida. Ela deveria ser inserida em um contexto diretamente humano, ao contrário de ser relegada exclusivamente aos museus ou galerias, compartimentalizada em teorias que distanciam as experiências estéticas da vida 
cotidiana - ou seja, do prazer pessoal que, segundo o autor, está próximo às coisas da natureza como o ar, o solo, a luz, as flores. As coisas esteticamente admiráveis brotariam desses lugares (DEWEY, 2010).

A Filosofia da Arte defendida por Dewey reestabelece a união entre as formas mais sofisticadas do artístico com os sentimentos mais ordinários da vida humana. $A$ constante interação entre sujeito e ambiente, juntamente com os resultados dessa relação, será o que constituirá uma experiência. Na relação entre a Arte e a Estética, o filósofo afirma que o trabalho poético, desenvolvido em uma perspectiva da filosofia da experiência, seria o clímax da sofisticação entre a união dos saberes afetivo, intelectual e prático (DEWEY, 2002). Na perspectiva do filósofo, as Artes oferecem vitalidade e aprofundam o conhecimento das experiências acumuladas, porque

[t]oda arte envolve órgãos físicos, como o olho e a mão, o ouvido e a voz e, no entanto, ela ultrapassa as meras competências técnicas que estes órgãos exigem. Ela envolve uma ideia, um pensamento, uma interpretação espiritual das coisas e, no entanto, apesar disto é mais do que qualquer uma destas ideias por si só. Consiste numa união entre o pensamento e o instrumento de expressão. (DEWEY, 2002, p. 76)

É justamente na integração entre o pensamento e o instrumento de expressão que se pode esboçar uma ideia do que o autor nos comunica a respeito da experiência singular/estética. A experiência para Dewey é um processo do viver que se relaciona de maneira intensa e contínua entre o mundo e o sujeito. Dessa relação brotam conflitos, resistências, impressões. Destes elementos, por sua vez, emergem as experiências, envoltas em ideias e emoções. É, portanto, neste conceito instaurado por Dewey que uma filosofia da experiência para a Arte/Educação contemporânea torna-se pertinente.

A experiência singular é também uma experiência estética, tendo em vista que em ambas as experiências há consumação, e nunca cessações - como no caso de uma experiência intelectual. Neste sentido, a experiência intelectual é diferente da experiência singular/estética. A primeira tem como matéria-prima símbolos e signos, e exige uma conclusão, um encerramento. É justamente por sua natureza conclusiva que gera incertezas. Ao contrário, a experiência singular/estética reside em fluxos constantes, possui lugares de repouso, unidade, e o seu desfecho é atingido por um 
movimento ordeiro e organizado. O material vivenciado, ao mesmo tempo em que é marcado pelas percepções, é transformado pelas experiências anteriores. "A conclusão é uma consumação, e não uma cessação. Esta experiência carrega um caráter individualizador e autossuficiente." (DEWEY, 2010, p. 110)

A experiência singular/estética é uma espiral, seu fluxo contínuo unifica a percepção entre o que é feito e o que é suportável; cria conexões com experiências anteriores - uma observação constante entre o que existiu, existe e existirá, o processo é vivenciado conscientemente. A ansiedade e as frustações, que fazem parte da vida cotidiana e estão presentes no processo criativo, não impedem que a inteligência organize a consumação da experiência pulsante; no discernimento entre ações e desejos, não há dicotomias, fragmentações entre inteligência e sensibilidade. Tudo se relaciona, tudo está junto, é o próprio processo do viver unificado ao ambiente tomando consciência de si - esse conjunto consciente propicia ao sujeito uma experiência singular/estética. O estético, na filosofia da Arte de John Dewey, não é um fator externo e que se "lança" para a experiência. Tampouco está relacionado ao luxo, ou é idealizado por qualquer corrente de pensamento transcendental. Para o autor, "o estético (...) é o desenvolvimento esclarecido e intensificado de traços que pertencem à toda experiência normalmente completa (...) estético refere-se à experiência como apreciação, percepção e deleite" (DEWEY, 2010, p. 125-127).

Dewey afirma que "a arte, em sua forma, une a mesma relação entre o agir e o sofrer, entre a energia de saída e a de entrada, que faz com que uma experiência seja uma experiência" (DEWEY, 2010, p. 128). Como o artístico está relacionado ao ato de produção e o estético ao ato de prazer e percepção, uma obra acontece em sua completude quando 0 artista, ao trabalhar, assume essas duas atitudes transformando-a em uma só, ou seja, numa atitude artístico-estética. O artista, na concepção de Dewey,

[...] comparado a seus semelhantes, é alguém não especialmente dotado de poderes de execução, mas também de uma sensibilidade inusitada às qualidades das coisas. Essa sensibilidade também orienta seus atos de criação" (DEWEY, 2010, p. 130). 
O que está em questão é o controle do desejo. Na ideia inicial até será possível pensar em tudo, mas o "tudo" não é possível na relação que se pretende produzir o artista encontra os obstáculos, as dificuldades da produção. Saber produzir neste limite da existência humana é aprender que a relação entre pensar e agir, culminando em uma experiência singular/estética e compreendendo que experiência não é uma soma entre o emocional e intelectual, mas que ambos ocorrem inseparavelmente, é uma das modalidades mais exigentes do pensamento. Chegar na consumação desta experiência é proteger o trabalho de uma mera sucessão de excitações (DEWEY, 2010). Sendo assim, a experiência singular/estética presente nos escritos de John Dewey é o lugar onde o autor nos esclarece sobre a proximidade desse conceito com o campo das artes e o trabalho do artista.

Dewey desafia toda a tradição filosófica acerca do conceito de estética. O autor coloca o estético, assim como as Artes, nas origens da existência humana. Ele revela que a experiência singular/estética deve estar presente nos processos normais do viver, nas coisas cotidianas da vida. Segundo Dewey (2010, p. 72), "se as obras de arte fossem colocadas em um contexto diretamente humano na estima popular, teriam um atrativo muito maior do que podem ter quando as teorias compartimentalizadas da arte ganham aceitação geral". O autor afirma ainda que "a genuína arte se desenvolve a partir do trabalho do artesão" (Dewey, 2002, p. 76), defendendo que o grande desenvolvimento proporcionado por um trabalho estético-artístico está associado à vida cotidiana, às coisas simples (DEWEY, 2002).

\section{Inquietações Pesquisantes}

Pensar é um ato, sentir é um fato. Clarice Lispector

É a partir desta perspectiva que os pressupostos filosóficos deweyianos falam de uma Filosofia da Arte como experiência. Consciente desse processo, a experiência possibilita ao indivíduo uma reorganização que o coloca em contato com outras formas de apreender a vida. Por isso, a experiência singular/estética é inerente à consumação, e nunca a uma conclusão. Entende-se por consumação "um certo nutrirse" constantemente da experiência que no seu fluxo-refluxo-repouso avança para 
novas reformulações, onde outras percepções irão envolver esses atos e ideias de pensamento. O pensar também ocorre em fluxos, que são fases carregadas de afetividade; não são evoluções, mas variações móveis (DEWEY, 2010).

No caso específico das Artes Visuais, a percepção é o sentido mais comum por onde os conteúdos de uma obra são "absorvidos". Em toda experiência singular/estética, tocamos o mundo através de um órgão específico. Será a partir desse órgão que a percepção encontrará o fluxo para operar em toda a sua energia. Essa, provocada exclusivamente pela obra de Arte, é "a maior realização intelectual da história da humanidade" (DEWEY, 2010, p. 93). O autor nos explica que:

\begin{abstract}
A obra de arte provoca e acentua essa característica de ser um todo e de pertencer ao todo maior e abrangente que é o universo em que vivemos. Essa é, a meu ver, a explicação da sensação de requintada inteligibilidade e clareza que temos na presença de um objeto vivenciado com intensidade estética. (DEWEY, 2010, p. 351)
\end{abstract}

A arte reside no próprio processo do viver. O homem utiliza os materiais ofertados pela natureza com a intenção de significar sua existência no mundo e ampliar sua própria vida. A existência da Arte é prova de que o homem é capaz de nutrir-se conscientemente no plano do significado, intervindo com todo o seu organismo, regulando, selecionando e reordenando sua vida. A arte não está dissociada dos processos do viver, pois com ela, e a partir dela, conferimos sentido à nossa vida, revelamos desejos e geramos impulsos para continuarmos existindo com uma certa sensação de pertencimento no mundo.

Assim, a experiência estética/singular da qual nos fala Dewey transcreve-se também em dimensões pedagógicas, pois perpassa a escolha, a seleção e o repertório do espectador. Toda Arte, que busca novas maneiras de pensar o mundo, diferente dos sistemas tradicionais e hegemônicos do conhecimento, "precisa educar seu público em novos modos de percepção. Assim, a arte é essencialmente educativa, não somente em seu aspecto instrumental, mas através do consumatório e do instrumental fundidos na experiência" (BARBOSA, 2001, p. 147).

É relevante salientar que este valor do ato expressivo, a matéria prima da experiência que Dewey revela em sua obra, tem grande aproximação com a 
organização das emoções e a objetividade. Porém, organização e objetividade, para o filósofo, não são "coisas simples" de serem alcançadas pelo organismo que, fragmentado pelo ambiente e imerso nas teorias reducionistas explora, na maioria das vezes, experiências incipientes.

A teoria deweyana da Arte como experiência toma 0 argumento da aprendizagem como uma tomada de consciência, ou seja, da apreensão do conjunto das experiências que vamos justapondo no percurso da vida. Nesse conjunto da aprendizagem, o saber e a consolidação do pensamento e da percepção são identificados como os fatores decisivos para que ela ocorra. Isso muitas vezes distancia a Filosofia da Arte como experiência dos discursos acadêmicos e escolares, tendo em vista o contexto plenamente utilitário e prático em que estas instituições estão inseridas.

\section{Referências}

AMARAL, Maria Nazaré de C. Pacheco. Dewey: filosofia e experiência democrática. São Paulo: Perspectiva, 2007.

BARBOSA, Ana Mae. John Dewey e o ensino da arte no Brasil. São Paulo: Cortez, 2001.

DEWEY, John. Arte como experiência. São Paulo: Martins Fontes, 2010.

DEWEY, John. Democracia e educação. São Paulo: Companhia Editora Nacional, 1959.

DEWEY, John. A escola e a sociedade: a criança e o currículo. Lisboa: Relógio D'água, 2002.

DEWEY, John. Vida e educação. São Paulo: Melhoramentos, 1971.

DUVE, Thierry de. Fazendo escola (ou refazendo-a?). Chapecó: Argos, 2012.

PAREYSON, Luigi. Os problemas da estética. São Paulo: Martins Fontes, 1984.

SHUSTERMAN, Richard. Vivendo a arte: o pensamento pragmatista e a estética popular. São Paulo: Editora 34, 1998.

TASSINARI, Alberto. O espaço moderno. São Paulo: Cosac Naify, 2001.

WESTBROOK, Robert B. TEIXEIRA, Anísio (trad. e org. José Eustáquio Romão, Verone Lane Rodrigues). John Dewey. Recife: Fundação Joaquim Nabuco: Editora Massangana, 2010. Coleção Educadores (MEC). Disponível em: http://www.dominiopublico.gov.br/download/texto/me4677.pdf

WOSNIAK, Fábio. A poética na prática de um pedagogo: experiência sobre aprender artes visuais através da pintura. 2015. $170 \mathrm{f}$. Dissertação (Mestrado em Artes Visuais) - Centro de Artes, Universidade do Estado de Santa Catarina, Florianópolis, 2015. 


\section{Fábio Wosniak}

Doutorando em Artes Visuais na Linha de Pesquisa de Ensino das Artes Visuais pelo Programa de Pós-Graduação em Artes Visuais da Universidade do Estado de Santa Catarina (PPGAV/UDESC). Mestre em Artes Visuais na Linha de Pesquisa de Ensino das Artes Visuais pelo PPGAV/UDESC. Pedagogo S.E./2012 FAED/UDESC; psicanalista; vice-coordenador da Rede de Educadores de Museus de Santa Catarina - REM/SC (Gestão 2013-2015); membro/pesquisador do Grupo de Pesquisa Entre Paisagem (UDESC/CNPQ) e integrante do Grupo de Estudos Estúdio de Pintura Apotheke (UDESC). Atua principalmente nos seguintes temas: Arte-Educação, Arte e Pedagogia, formação docente em Artes Visuais.

E-mail: fwosniak@gmail.com

Currículo: http://lattes.cnpq.br/6525393533253057

\section{Jociele Lampert}

Desenvolveu pesquisa como professora visitante no Teachers College na Columbia University na cidade de New York como Bolsista Fulbright (2013), onde realizou estudo intitulado: Artist's Diary and Professor's Diary: Roamings about Painting Education. Doutora em Artes Visuais pela Escola de Comunicações e Artes da Universidade de São Paulo (ECA/USP - 2009); Mestre em Educação pela Universidade Federal de Santa Maria (UFSM - 2005). Possui Graduação em Desenho e Plástica Bacharelado em Pintura, pela Universidade Federal de Santa Maria (2002) e Graduação em Desenho e Plástica Licenciatura pela Universidade Federal de Santa Maria (2003). Professora Associada na Universidade do Estado de Santa Catarina. Atua no Mestrado e Doutorado em Artes Visuais PPGAV/UDESC, como orientadora na Linha de Pesquisa de Ensino de Arte e na Graduação em Artes Visuais DAV/UDESC. É membro do Grupo de Estudos e Pesquisa em Arte, Educação e Cultura UFSM/CNPq. Membro/Líder do Grupo de Pesquisa Entre Paisagens UDESC/CNPq. Coordenadora do Grupo de Estudos Estúdio de Pintura Apotheke (UDESC). E Editora-chefe do periódico Revista Apotheke. Tem experiência na área de Artes Visuais, atuando principalmente nos seguintes temas: pintura, Arte e Educação, formação docente. É membro associado da ANPAP.

E-mail: jocielelampert@uol.com.br

Currículo: http://lattes.cnpq.br/7149902931231225

Recebido em 10 de março de 2016 Aceito em 30 de julho de 2016 